\title{
Erratum to: Photochemistry of Ions at D-region Altitudes of the Ionosphere: A Review
}

\author{
A. V. Pavlov ${ }^{1}$
}

Published online: 6 June 2015

(C) Springer Science+Business Media Dordrecht 2015

\section{Erratum to: Surv Geophys (2014) 35:259-334 \\ DOI:10.1007/s10712-013-9253-z}

The effective photoelectron ionization cross sections of the formation of $\mathrm{N}_{2}^{+}$and $\mathrm{N}^{+}$ions from $\mathrm{N}_{2}$ found from the ratios of photoelectron impact ionization to direct photoionization for $\mathrm{N}_{2}^{+}$and $\mathrm{N}^{+}$ions (Solomon and Qian 2005) were considered in the early version of the review by Pavlov (2014). In Table 1 of the review by Pavlov (2014), these effective photoelectron ionization cross sections were presented instead of the average photoionization cross sections of the formation of $\mathrm{N}_{2}{ }^{+}$and $\mathrm{N}^{+}$ions from $\mathrm{N}_{2}$ whose values taken from Solomon and Qian (2005) are given here in Table 1.

The review by Pavlov (2014) contains a typographic error in the total rate coefficient, $K_{\text {tot }}$, of the $\mathrm{ONOO}^{-}+\mathrm{O}_{3} \rightarrow \mathrm{O}_{3}{ }^{-}+\mathrm{NO}+\mathrm{O}_{2}$ and $\mathrm{ONOO}^{-}+\mathrm{O}_{3} \rightarrow \mathrm{NO}_{2}{ }^{-}+2 \mathrm{O}_{2}$ reactions [reactions 100 and 101 of Table 10 given by Pavlov (2014)]. The correct value of $K_{\text {tot }}$ is equal to $7.5 \times 10^{-10}\left(300 / T_{\mathrm{n}}\right)^{1.16} \mathrm{~cm}^{3} \mathrm{~s}^{-1}$ where $T_{\mathrm{n}}$ is the neutral temperature expressed in Kelvins. This rate coefficient was measured by Viggiano et al. (2006) at 200 and $300 \mathrm{~K}$ temperature, and it was assumed by Pavlov (2014) that the temperature dependence of $K_{\text {tot }}$ follows a power law. Over $87 \%$ of the $\mathrm{ONOO}^{-}+\mathrm{O}_{3}$ reaction proceeded by producing $\mathrm{O}_{3}{ }^{-}+\mathrm{NO}+\mathrm{O}_{2}$, and the amount of $\mathrm{NO}_{2}{ }^{-}$and $2 \mathrm{O}_{2}$ was less than $13 \%$ of the products (Viggiano et al. 2006).

Author correction belated.

The online version of the original article can be found under doi:10.1007/s10712-013-9253-z.

A. V. Pavlov

pavlov@izmiran.ru

1 Pushkov Institute of Terrestrial Magnetism, Ionosphere and Radio-Wave Propagation of the Russian Academy of Sciences (IZMIRAN), Moscow, Troitsk 142190, Russia 
Table 1 The average photoionization cross sections of the formation of $\mathrm{N}_{2}+$ and $\mathrm{N}^{+}$ions from $\mathrm{N}_{2}$ in the wavelength range, $\lambda_{j}$ (Solomon and Qian 2005)

\begin{tabular}{lrll}
\hline$j$ & $\lambda_{j}(\mathrm{~nm})$ & \multicolumn{2}{l}{$\sigma_{\text {in }}\left(\lambda_{j}\right)\left(10^{-18} \mathrm{~cm}^{2}\right)$} \\
\cline { 3 - 4 } & & $\mathrm{N}_{2}^{+}$ & $\mathrm{N}^{+}$ \\
\hline 1 & $0.05-0.4$ & $1.000 \times 10^{-4}$ & $2.400 \times 10^{-3}$ \\
2 & $0.4-0.8$ & $8.040 \times 10^{-4}$ & $1.930 \times 10^{-2}$ \\
3 & $0.8-1.8$ & $5.636 \times 10^{-3}$ & 0.1353 \\
4 & $1.8-3.2$ & $4.548 \times 10^{-2}$ & 1.092 \\
5 & $3.2-7.0$ & 0.2480 & $9.754 \times 10^{-2}$ \\
6 & $7.0-15.5$ & 1.147 & 0.3803 \\
7 & $15.5-22.4$ & 3.799 & 1.287 \\
8 & $22.4-29.0$ & 7.493 & 2.445 \\
9 & $29.0-32.0$ & 10.66 & 1.092 \\
10 & $32.0-54.0$ & 19.57 & $9.826 \times 10^{-2}$ \\
11 & $54.0-65.0$ & 23.09 & 0.000 \\
12 & $65.0-79.8$ & 15.64 & 0.000 \\
13 & $65.0-79.8$ & 23.39 & 0.000 \\
\hline
\end{tabular}

The $\mathrm{O}^{-}+\mathrm{O} \rightarrow \mathrm{O}_{2}+\mathrm{e}, \mathrm{O}_{2}^{-}+\mathrm{O} \rightarrow \mathrm{O}_{3}+\mathrm{e}$, and $\mathrm{O}_{2}{ }^{-}+\mathrm{O} \rightarrow \mathrm{O}^{-}+\mathrm{O}_{2}$ reaction rate coefficients measured by Belostotsky et al. (2005) (first reaction) and Poutsma et al. (2006) (second and third reactions) at room temperature were recommended by Pavlov (2014) for ionospheric studies. Published temperature dependences of these rate coefficients were not reviewed by Pavlov (2014).

The $\mathrm{O}^{-}+\mathrm{O} \rightarrow \mathrm{O}_{2}+$ e reaction rate coefficient was measured by Ard et al. (2013) in the temperature range of $173-500 \mathrm{~K}$, and the temperature dependence of this rate coefficient was approximated by Ard et al. (2013) as $1.5 \times 10^{-10}\left(300 / T_{\mathrm{n}}\right)^{1.3} \mathrm{~cm}^{3} \mathrm{~s}^{-1}$. If the temperature is changed from 173 to $400 \mathrm{~K}$, then the measured total rate coefficient of the $\mathrm{O}_{2}{ }^{-}+\mathrm{O} \rightarrow \mathrm{O}_{3}+\mathrm{e}$ and $\mathrm{O}_{2}{ }^{-}+\mathrm{O} \rightarrow \mathrm{O}^{-}+\mathrm{O}_{2}$ reactions can be approximated as $1.7 \times 10^{-10}\left(300 / T_{\mathrm{n}}\right)^{1.8} \mathrm{~cm}^{3} \mathrm{~s}^{-1}$ (Ard et al. 2013). Branching ratios for this reaction were determined to be less than $55 \%$ for the $\mathrm{O}_{3}+$ e channel and larger than $45 \%$ for the $\mathrm{O}^{-}+\mathrm{O}_{2}$ channel at room temperature (Poutsma et al. 2006). For definiteness, these branching ratios were taken to be equal to 55 and $45 \%$ by Pavlov (2014), respectively. On the other hand, the equal branching ratios are recommended by Albritton (1978) for this reaction, and this approach results in the rate coefficient of $8.5 \times 10^{-11}\left(300 / T_{\mathrm{n}}\right)^{1.8}$ $\mathrm{cm}^{3} \mathrm{~s}^{-1}$ for each of the $\mathrm{O}_{2}^{-}+\mathrm{O} \rightarrow \mathrm{O}_{3}+\mathrm{e}$ and $\mathrm{O}_{2}^{-}+\mathrm{O} \rightarrow \mathrm{O}^{-}+\mathrm{O}_{2}$ reactions.

The reactions of $\mathrm{O}^{-}$and $\mathrm{O}_{2}^{-}$with $\mathrm{N}$ were not discussed by Pavlov (2014). The $\mathrm{O}^{-}$ $+\mathrm{N} \rightarrow \mathrm{NO}+$ e reaction rate coefficient was measured by Ard et al. (2013) in the temperature range of $173-500 \mathrm{~K}$, and the temperature dependence approximation of this rate coefficient was given by Ard et al. (2013) as $1.7 \times 10^{-10}\left(300 / T_{\mathrm{n}}\right)^{0.6} \mathrm{~cm}^{3} \mathrm{~s}^{-1}$. The $\mathrm{O}_{2}{ }^{-}+\mathrm{N}$ total reaction rate coefficient measured in the temperature range from 173 to $400 \mathrm{~K}$ was represented by Ard et al. (2013) as $3.1 \times 10^{-10}\left(300 / T_{\mathrm{n}}\right)^{1.7} \mathrm{~cm}^{3} \mathrm{~s}^{-1}$. The resulting product distribution for this reaction was found to be larger than $85 \%$ for the $\mathrm{NO}+\mathrm{O}^{-}$channel and less than $15 \%$ for the $\mathrm{NO}_{2}+$ e channel (Ard et al. 2013). 


\section{References}

Albritton DL (1978) Ion-neutral reaction-rate constants measured in flow reactors through 1977. At Data Nucl Data Tables 22(1):1-89

Ard SG, Melko JJ, Jiang B, Li Y, Shuman NS, Guo H, Viggiano AA (2013) Temperature dependences for the reactions of $\mathrm{O}_{2}{ }^{-}$and $\mathrm{O}^{-}$with $\mathrm{N}$ and $\mathrm{O}$ atoms in a selected-ion flow tube instrument. J Chem Phys 139(14): 144302. doi:10.1063/1.4824018

Belostotsky SG, Economou DJ, Lopaev DV, Rakhimova TV (2005) Negative ion destruction by $\mathrm{O}\left({ }^{3} \mathrm{P}\right)$ atoms and $\mathrm{O}_{2}\left(\mathrm{a}^{1} \Delta_{\mathrm{g}}\right)$ molecules in an oxygen plasma. Plasma Sources Sci Technol 14(3):532-542

Pavlov AV (2014) Photochemistry of ions at D-region altitudes of the ionosphere: a review. Surv Geophys 35:259-334. doi:10.1007/s10712-013-9253-z

Poutsma JC, Midey AJ, Viggiano AA (2006) Absolute rate coefficients for the reactions of $\left.\mathrm{O}_{2}{ }^{-}+\mathrm{N}^{4} \mathrm{~S}_{3 / 2}\right)$ and $\mathrm{O}_{2}{ }^{-}+\mathrm{O}\left({ }^{3} \mathrm{P}\right)$ at $298 \mathrm{~K}$ in a selected-ion flow tube instrument. J Chem Phys 124(7):074301

Solomon SC, Qian L (2005) Solar extreme-ultraviolet irradiance for general circulation models. J Geophys Res 110(10):A10306. doi:10.1029/2005JA011160

Viggiano AA, Midey AJ, Ehlerding A (2006) Kinetics of the reactions of $\mathrm{ONOO}^{-}$with small molecules. Int J Mass Spectrom 255-256(1):65-70 